THURSDAY, NOVEMBER 24, Igro.

\section{HIGHER ASPECTS OF ELECTRICITY.}

A Treatise on Electrical Theory and the Problem of the Universe, considered from the Physical Point of View, with Mathematical Appendices. By G. W. de Tunzelmann. Pp. xxxii +654 . (London: Charles Griffin and Co., Ltd., Igro.) Price ${ }_{5} 5$. net.

THE partial success which has attended the recent attempts of Einstein and Minkowski to found an electromagnetic system of mechanics has tended to strengthen the popular idea that the solution of outstanding problems and mysteries must be sought in the domain of electrical rather than other physical phenomena. From being a disturbing element characterised by unaccountable vagaries, the "electric fire" has come to be an all-pervading element, closely approaching the alchemist's idea of a primal substance. Mr. de Tunzelmann's work is an ambitious attempt to apply the Faraday-Maxwell theory of electricity, as modified by Larmor in the atomistic direction, to what he calls "the problem of the universe." Incidentally, the book gives a great deal of information with regard to recent work and speculation, and although the titular object of the work has not been attained (it could hardly be otherwise in our present state of knowledge), it will be valued on account of the information given on such varied subjects as electrolysis, radiation, radio-activity, the age of the earth, the solar corona, and the place of mind in the universe.

As might have been expected in a book of this kind, the interstellar ether plays a fundamental part in most of the ultimate speculations. That being so, it is to be regretted that no serious attempt was miade to present the modern aspects of the various ether theories. Possibly the author may have considered the matter as too controversial. The electromagnetic principle of relativity (as distinguished from the mechanical ()r Newtonian one) is of such outstanding importance that it is quite impossible to state modern electrical problems without at least acknowledging its existence. Yet, neither in chapters v. nor xxii., where some statement of the principle is urgently called for, nor indeed in any other part of the work, is it even mentioned. And, although Le Sage's hypothesis and its later variants are dealt with to a remarkably full extent, there is no reference to $\mathrm{H}$. Witte and his proof that the only chance for a mechanical explanation of electrical phenomena lies in the assumption of an ether composed of discrete particles.

Of minor blemishes we have "cathion" instead of "cation" (p. 19) evidently due to mistaken etymology, a micromillimetre described as "a thousandth of a millimetre" (p. 32 ) , "coronarium" instead of "coronium" (p. 37I), and plain "Norman Lockyer" (p. 644) beside the full titles of other savants. In dealing with magnetism, Langevin's important and successful theory, based upon the Zeeman effect and Curie's law, is not mentioned. In dealing with light, NO. 2 I 43 , VOL. 85$]$ the author suggests calling the velocity of light in space the "radiation constant" (a term already otherwise appropriated), and (p. 271) makes out that an absorbing body absorbs less (instead of more) energy in unit time on being moved in the direction from which the light is coming.

The chapter on "The Place of Mind in the Universe," is a fascinating one, though its connection with the main work is not very obvious. The author aims at an all-embracing system or hierarchy of ultimate realities, beginning at the absolute, or eternal self-consciousness, and passing through mind, energy, and ether down to matter. The chapter is well written, and most suggestive. It is, of course, open to criticism on many points, but as few physicists have the courage to penetrate far into that borderland on the confines of which they, more than others, are wont to dwell, a spirited attempt like the present deserves every encouragement. At a time when the ether is being tried for its very existence, it is unwise to describe such a philosophic scheme as based upon a substance the properties of which, as the writer somewhat hastily asserts, "are derived from empirical observation." And when that svstem is further "strengthened" by a reference to the discarded "Nrays," and a single experiment in thought transference unaccompanied by the elementary safeguards devised by the Psychical Research Society, the system put forward is placed at a disadvantage from the first. Nor is that disadvantage removed by too great an insistence on the principle of the conservation of energy, and its use to assign a time-limit to the existence of the visible universe. Such a time-limit is really a negation of science and philosophy, as it implies that deus ex machina from which all scientific achievement has had to liberate itself or perish.

There are eighteen appendices on miscellaneous electromagnetic and philosophical subjects. Many of these, especially that on astronomical anomalies, are very useful and valuable.

E. E. F.

\section{TECHNICAL DICTIONARIES.}

The Deinhardt-Schlomann Series of Technical Dic. tionaries in Six Languages. By Alfred Schlomann. Vol. v., Railway Construction and Operation. Pp. xiii +87 o. Price r2s. net. Vol. vi., Railway Rolling Stock. Compiled by Dipl.-Ing. August Boshart. Pp. xiii +796 . Price ros. 6d. net. (I.ondon: Constable and Co., Ltd.; Munich and Berlin: R. Oldenbourg, 1909.)

THESE two volumes form part of a series of tech1 nical dictionaries in six languages-English, Spanish, German, Russian, French, and Italian-of which seven volumes have now appeared. They are edited and compiled by Messrs. Deinhardt and Schlomann, assisted by experts from all the leading countries in each branch of the subject. The essential features of the scheme are that the six languages are all on one page, and, wherever it is possible, sketches are given so as to elucidate the text and facilitate the use of the dictionary. At the end of each volume complete alphabetical indexes are given, 